\title{
Sonorona o el rizoma de la cultura digital. Um estudio de caso 1
}

\author{
Mónica María López Gili \& Félix Angulo Rascoii \\ Universidade de Cádiz, Espanha
}

\begin{abstract}
Resumo
Este artigo apresenta o estudo de caso de Sonorona, nick de Maria, uma jovem de 22 anos com participação ativa no YouTube e em blogues. A sua realização teve como objetivo analisar a compreensão e participação que a juventude tem da/na cultura mediática e tecnológica que a rodeia. Esta finalidade encontra-se na linha dos estudos desenvolvidos por Sefton-Green (1998), Hutchby e Moran-Ellis (2001), Facer, Furlong, e Furlong (2003), entre outros, em relação às profundas mudanças que causaram o surgimento dos avanços tecnológicos, configurando mesmo o que poderia ser chamado de um novo paradigma cultural caracterizado pelo digital. As tecnologias que nos rodeiam e com que convivemos têm transformado a maneira como as pessoas se relacionam, mas também o modo como nos relacionamos com a informação e o conhecimento e como a identidade se desenvolve.
\end{abstract}

\section{Palavras-Chave}

Literacia digital; Identidade na Rede; Juventude; Educação informal

\section{Introducción}

Existen especialmente dos lugares comunes en la literatura sobre la utilización de las tecnologías de la información y la comunicación que quizás tengamos que revisarlos. Uno tiene que ver con la misma denominación generacional, es decir, con el modo en que nos referimos a las nuevas generaciones - modos que tienden más a la hipérbole y a la hipertrofia que a 
la corrección conceptual (Angulo Rasco \& Bernal, 2012). Se ha hablado y se habla de Generación Net (Tapscott, 1998), de Nativos Digitales (Prensky, 2001a, 2001b, 2011a, 2011b) ${ }^{2}$, de MySpace Generation (Ante \& Holahan, 2008), de Youtubers (Burgess \& Green, 2009), de Look-at-me-Generation (Orlet, 2007), de Google Generation (Williams \& Rowlands, 2007) y, last but not least, Kress (2010) sugiere la idea de Screen Generation.

Lo que subyace a esta diversidad es la fuerte impronta tecnológica, como si se hubiera revitalizado el determinismo tecnológico (Warschauer, 1999) ${ }^{3}$. Sin embargo, todas ellas dejan fuera quizás lo más importante: que durante los últimos 100 años hemos ido construyendo e introduciendo una nueva cultura (Bolter \& Grusin, 1999; Gere, 2002; Angulo Rasco \& Vázquez Recio, 2010). Lo que nos lleva al segundo lugar común, es decir, dónde estamos y de qué trata esta nueva situación o entorno densamente tecnologizado 4 . Aquí, la tendencia es a enfatizar la tecnología, el digitalismo o el informacionismo (Castells, 1997, 2001, 2006).

No tenemos ningún problema aceptando las calificaciones que Castells ha ido adoptando; tampoco con la más comprensiva de tercer entorno de Echeverría (1999). Estamos convencidos, no obstante, que una mejor comprensión de lo que actualmente la juventud hace o deja de hacer en este nuevo entorno requiere convocar la idea de cultura y, específicamente, la idea de cultura digital ${ }^{5}$. Al menos por tres razones. Una proviene del análisis histórico: cualquier cambio en los medios de comunicar y expresar supone un cambio y una transformación cultural (Angulo Rasco, 2008). La segunda, del hecho de que la cultura digital no es una cultura aislada o, dicho de otra manera, un acontecimiento singular. Como han advertido Bolter y Grusin (1999), nos encontramos con un proceso de remediación, en el que unas culturas se montan y se expanden abarcando los logros de las anteriores ${ }^{6}$. La aparición de la cultura digital no ha supuesto la ruptura con las culturas orales, lecto-escritoras o audiovisuales; al contrario, de la misma manera que como las anteriores lo han hecho, la cultura digital aprovecha e incrementa el potencial de la oralidad, la lecto-escritura y lo audiovisual ${ }^{7}$. La tercera es una razón más particular y relativa a nuestro caso. Centrarnos en la cultura digital nos permite analizar elementos clave de la juventud como la identidad, sus procesos de comunicación, sus actuaciones sociales y sus construcciones cognitivas. La idea de cultura digital nos permite ir más allá de las herramientas y aparatos digitales: al corazón de los fenómenos que se están 
produciendo. De esta manera, entender lo que implica la cultura digital, con independencia de características como su hibridación, multimodalidad e hipertextualidad (Angulo Rasco \& Vázquez Recio, 2010), nos permite acercarnos a lo que quizás sólo pueda ser denominado rizoma.

\section{Taxonomías, misceláneas y rizomas}

Cuando Linneo publicó, en 1740, su Systema Naturae estaba estableciendo una taxonomía del conocimiento de los seres vivos, ordenándolos en niveles jerárquicos, según estructuras arbóreas (Weinberger, $2005,2007)$. Este sistema se ha mantenido con pocas variaciones hasta la llegada de la arquitectura digital. Una arquitectura que rompe con este sistema, impelida por la sobre-abundancia informacional que genera la tecnología, su difusión y su apertura. Este proceso conlleva, no sólo la descentración jerárquica con respecto a un orden establecido por expertos de lo que debe ser el conocimiento organizado, sino que, con mayor razón, representa un notable reto a cualquier intento de acceso al mismo, de búsqueda y de clasificación. Como indica Weinberger (2005), ya no tenemos datos ordenados en casilleros fijos; tenemos datos en capas superpuestas. Así, "La información no sólo quiere ser libre; quiere ser miscelánea" (p. 7) ${ }^{8}$ y "El orden misceláneo está cambiando cómo pensamos que el mundo mismo está organizado e incluso quién tiene la autoridad para decírnoslo" (p. 23).

Pero aceptando el valor de lo misceláneo para el conocimiento y la cognición, nos quedaríamos en un aspecto, importante, pero limitado, de lo que implica la cultura digital. Lo mismo nos ocurriría si nos detuviéramos en la hipertextualidad como modo de presentación de la información en las pantallas y en los textos digitales. $E$ incluso si nos remitimos exclusivamente a la idea de mashup culture (cultura de mezcla) (Ito, 2010; Sonvilla-Weiss, 2010). Se trata siempre de aspectos esenciales, pero insuficientes para abarcar en profundidad el enorme cambio que estamos generando y en el que gran parte de nuestra juventud se encuentra implicada. Necesitamos un concepto con una mayor fuerza heurística. Necesitamos hablar del rizoma.

Rizoma es un concepto propuesto por Gilles Deleuze y Félix Guattari (1997) para ofrecernos una espíteme que nos posibilita entender o aproximarnos a la complejidad de la cultura digital como forma de vida ${ }^{9}$. A 
diferencia de una estructura arbórea - el árbol raíz -, el rizoma es la conexión y la heterogeneidad: "Un rizoma no cesaría de conectar eslabones semióticos, organizaciones de poder, circunstancias relacionadas con las artes, las ciencias, las luchas sociales" (Deleuze \& Guattari, 1997, p. 18). Un rizoma también es multiplicidad substantiva: "Las multiplicidades son rizomáticas y denuncian las pseudomultiplicidades arborescentes. (...) Una multiplicidad no tiene ni sujeto ni objeto, sino únicamente determinaciones, tamaños, dimensiones que no pueden aumentar sin que ella cambie de naturaleza" (Deleuze \& Guattari, 1997, p. 19). Y un rizoma es también una ruptura asignificante: "(...) puede ser roto, interrumpido en cualquier parte, pero siempre recomienza según ésta o aquella de sus líneas y según otras" (Deleuze \& Guattari, 1997, p. 22).

Recapitulemos. Al invocar la idea de cultura digital estamos conjugando el terreno propio del rizoma; un ámbito que es múltiple, constantemente cambiante (no acumulativo) e irrompible. Los rizomas son esa conexión constante que se 'ramifica' a sí misma y que, con ello, olvida el centro; no hay un lugar privilegiado en un rizoma: hay lugares cambiantes; no hay una sola identidad, sino identidades móviles y diversas (Deleuze \& Guattari, 1971). La cultura digital es rizomática y se realiza como tal. En lo que sigue se presentará, a través del caso de una joven - gurú del makeup-, parte de las dimensiones rizomáticas de la cultura digital. Lo que mostramos es una aproximación parcial de un estudio de caso más extenso.

\section{Aspectos metodológicos}

Los objetivos de este estudio se encuentran tanto en comprender el uso de las tecnologías digitales, como, fundamentalmente, su incidencia en la propia construcción de la cultura y del conocimiento de una "webactriz" (Pisani \& Piotet, 2009), tal y como se genera en su contexto. La búsqueda de los significados e interpretaciones que subyacen a práctica, acciones y vida digital de la webactriz, conocer y comprender no sólo qué hace, sino cómo lo hace, por qué lo hace y dónde lo hace, necesitó y exigió consecuentemente el uso de técnicas metodológicas cualitativas.

El estudio de casos es el modo más adecuado para conocer, de primera mano, las experiencias y los esquemas de pensamiento de la 
informante, de tal manera que permita explicar cómo y por qué ocurren los sucesos (Stake, 1995). El estudio se centró en el análisis de lo particular, lo singular, lo exclusivo (Simons, 2011, p. 19), a través del análisis de un fenómeno actual en un contexto real (Yin, 1994, p. 1).

Nuestro análisis se basa en un trabajo de campo que ha constado de: diez observaciones no participantes durante el tiempo de creación de contenidos; aproximadamente mil horas de observaciones de sus intervenciones digitales, siete entrevistas semiestructuradas y más de cuatrocientas horas de conversaciones informales; además de recogida de imágenes (más de doscientas), pantallazos, descarga de sus vídeos, y anotaciones en el cuaderno y el diario de campo.

Al tratarse de un estudio de caso sobre lo digital, el trabajo de campo no podía transcurrir sólo en la vida offline de la informante, sino también, y expresamente, en su vida digital (online). De este modo, el trabajo de campo y el desarrollo de las técnicas de investigación se desarrollaron tanto dentro como fuera de Internet (Miller \& Slater, 2000).

El entorno virtual es el contexto en el que se sucedían eminentemente las prácticas y experiencias digitales; pero tales experiencias se extrapolan fuera de las pantallas (Turkle, 1997). De ahí que se recogieron datos tanto dentro como fuera de la Red. Del mismo modo, la Internet se configuró con una doble dimensión: como objeto de estudio y como medio donde tuvo lugar el trabajo de campo; se investigó sobre las TIC y en las TIC, al mismo tiempo.

El estudio de caso se apoyó en técnicas de recogida de información cualitativas. En la observación etnográfica, siguiendo a Spradley (1980), Hine (2000) o Angrosino y Rosenberg (2011), se analizaron espacios (donde ocurrían los procesos de enseñanza y aprendizaje con y en las tecnologías digitales y el desarrollo de las creaciones de contenido y espacios privados como el hogar o el dormitorio), personas (la propia informante), acciones (lo que se hacía y no con Internet y el teléfono móvil), objetos, acontecimientos, interrelaciones (entre los dispositivos y las personas intervinientes) y tiempo, objetivos y sentimientos. Estas sesiones de observación tuvieron lugar: de forma online, sobre las relaciones con suscriptores/as, los contenidos creados, la participación en las redes sociales y espacios de creación y relación; y offline, sobre las sesiones de preparación de contenidos.

Otras estrategias fueron la entrevista semiestructurada y la conversación informal online: a través de sistemas de comunicación 
sincrónica, videollamadas, e-mails, mensajes privados en redes sociales, etc.; y offline: encuentros personales en distintos espacios físicos y tiempos (Westby, 1990; Mann \& Stewart, 2000; Angulo Rasco \& Vázquez Recio, 2003; Kozinets, 2010; Creswell, 2011; Prosser, 2011; Angrosino \& Rosenberg, 2011). Junto a ello se recogieron imágenes fijas y móviles (Becker, 1995; Denzin, 1997; Hine, 2000; Pink 2007) como fuente de datos para el análisis social, cultural y educativo.

Adjuntamos una tabla en la que se resumen los instrumentos de recogida de información, así como aquellos objetivos de cada uno de ellos.

\begin{tabular}{|c|c|c|}
\hline $\begin{array}{l}\text { INSTRUMENTO DE } \\
\text { RECOGIDA DE } \\
\text { INFORMACIÓN }\end{array}$ & PUNTO DE MIRA & INTENCIONES \\
\hline $\begin{array}{l}\text { OBSERVACIÓN } \\
10 \text { sesiones } \\
+ \text { de } 1.000 \text { horas de } \\
\text { observación de sus } \\
\text { intervenciones }\end{array}$ & $\begin{array}{l}\text { PC, decoración del mismo, otras } \\
\text { tecnologías utilizadas, vídeos, } \\
\text { producciones, creación de } \\
\text { producciones... }\end{array}$ & $\begin{array}{l}\text { Tomar contacto con los } \\
\text { informantes. } \\
\text { - Analizar aspectos que vayan a } \\
\text { trabajarse en las entrevistas. } \\
\text { - Contrastar las informaciones, } \\
\text { reflexiones y acciones. }\end{array}$ \\
\hline 7 entrevistas semiestructuradas & $\begin{array}{l}\text { Jóvenes que, además de } \\
\text { usuarios/as, son creadores/as de } \\
\text { contenidos con y para las } \\
\text { tecnologías. } \\
\text { En casos puntuales, amistades, } \\
\text { familiares, seguidores/as... }\end{array}$ & $\begin{array}{l}\text { - Profundización en los ámbitos } \\
\text { de información y problemáticas } \\
\text { de estudio. } \\
\text { - Tomar, de primera mano, } \\
\text { experiencias, impresiones y } \\
\text { sentimientos en torno a las } \\
\text { cuestiones de indagación. }\end{array}$ \\
\hline $\begin{array}{l}\text { CONVERSACIONES } \\
\text { INFORMALES } \\
+ \text { de } 400 \text { horas }\end{array}$ & $\begin{array}{l}\text { Todos los agentes implicados en } \\
\text { el estudio. }\end{array}$ & $\begin{array}{l}\text { Toma de aquella información } \\
\text { que no ha sido recogida de } \\
\text { modo formal (observaciones y } \\
\text { entrevistas). }\end{array}$ \\
\hline $\begin{array}{l}\text { RECOGIDA DE IMÁGENES } \\
\text { (FIJAS O MÓVILES) } \\
200 \text { imágenes fijas, } \\
\text { aproximadamente }\end{array}$ & $\begin{array}{l}\text { Espacios, dispositivos, } \\
\text { organización, cambios en dicha } \\
\text { organización de las tecnologías... }\end{array}$ & $\begin{array}{l}\text { - Recogida "indirecta" de } \\
\text { información sobre el informante } \\
\text { - Conocer las transformaciones } \\
\text { de los espacios físicos de uso } \\
\text { de las tecnologías digitales. } \\
\text { - Conocer sus relaciones con las } \\
\text { concepciones de los } \\
\text { informantes sobre la temática } \\
\text { estudiada. }\end{array}$ \\
\hline $\begin{array}{c}\text { DIARIO Y CUADERNO DE } \\
\text { CAMPO }\end{array}$ & $\begin{array}{l}\text { La propia investigación en todos } \\
\text { sus aspectos, las dudas, } \\
\text { reflexiones, intenciones, } \\
\text { conflictos, avances... }\end{array}$ & $\begin{array}{l}\text { - Recogida de todo el proceso de } \\
\text { preparación, desarrollo y } \\
\text { conclusión de la investigación. }\end{array}$ \\
\hline
\end{tabular}

Tabla 1 - Estrategias e instrumentos de recogida de información 


\section{Sonorona-María}

Sonorona tiene 22 años, nació en Cádiz, ha finalizado la Licenciatura de Ciencias del Mar y Ambientales y se ha convertido, en los últimos cuatro años, en gurú del makeup. Esta gaditana tiene intereses y aficiones relacionadas con el arte y la creatividad, tales como la pintura, la música, la fotografía, el diseño de moda, las manualidades y, claro, el mundo del maquillaje y la cosmética. Es seguida en YouTube por más de 90.000 personas, además de 13.000 en Twitter; tiene 3.000 suscripciones en su web/blog (www.sonorona.com) y 22.500 en Facebook, entre otras redes sociales como Instagram (con más de 21.000 followers). Cuatro años pueden parecer escasos, pero su ritmo de participación activa y la dimensión de su intervención han sido, y están siendo, vertiginosos y profundos.

Podemos afirmar que Sonorona es una de las youtubers andaluzas más conocidas y queridas. Sin embargo, María no tiene estudios formales en maquillaje ni en cosmética, tampoco en lo que a informática o tecnologías se refiere, pero sus tutoriales son vistos sobre todo en España y Latinoamérica. Sonorona utiliza y gestiona con precisión medios y herramientas de la cultura digital relacionados con la edición de imágenes, programación de webs o dispositivos de almacenamiento de información y plataformas de entorno colaborativo. Pero también ha aprendido a desenvolverse en la tecnología del makeup. Una y otra tecnología se mezclan en un mismo espacio físico: la habitación de María. Sonorona y María son la misma persona; pero no son lo mismo. Su entrelazar en la cultura digital marca la diferencia. Por ello, comprender la transición de María a Sonorona y su inter-relación supone analizar la trayectoria de Sonorona, las transformaciones que han sufrido su identidad y sus prácticas - es decir, el sentido rizomático de Sonorona.

\section{Entrada en la cultura digital: de la periferia al rizoma}

Sonorona se incorporó en primer lugar a la comunidad de YouTube para compartir sus conocimientos (y sus dudas) en lo que a maquillaje y belleza se refiere. Pero su incorporación a esta comunidad, así como en otras tales como Facebook, Instagram, Twitter..., en las que se ha ido introduciendo posteriormente, ha supuesto también el abandono de otras y la elaboración de una densa red complementaria de las tecnologías para difundir sus ideas y 
ponerse en contacto con sus seguidores/as. Nos acercaremos al mundo de Sonorona, a sus actividades digitales y al proceso de construcción de contenidos que sigue, para así entender la interrelación entre ambas identidades, las cuales no están en conflicto, como podría parecer.

El proceso de María a Sonorona ha pasado por una serie de etapas que van desde una participación mínima y en silencio en las redes sociales hasta una participación activa y profunda. Estas fases se han sucedido de forma paulatina y, a veces, simultánea.

Sonorona comenzó su andadura siendo consumidora de cultura digital, desde una posición distante y de observación lindante sobre lo que ocurría en el mundo virtual. Esta situación le permitió acceder a las características que determinaban las comunidades que frecuentaba y sus prácticas: "sólo miraba y me fijaba en lo que hacían las demás para yo aprender, las imitaba" [extracto de entrevista a Sonorona, 2010]. En esta etapa, se suscribió a canales en YouTube, se hizo seguidora de quien le interesó en Twittere incorporó nuevas 'amistades' en Facebook y en Tuenti ${ }^{10}$. Su participación era pasiva y desde la periferia: accedía a las prácticas, a los acontecimientos, pero no intervenía ni interfería con ellos. Sonorona era aquí un árbol, o más bien, la rama de un árbol.

Sin embargo, pronto comenzó a convertirse en raíz y a romper su silencio y anonimato anterior. El momento de la eclosión ocurrió al subir un vídeo a YouTube con el fin de participar en un concurso organizado por una youtuber. Con esta participación, que supuso la presentación pública de Sonorona, obtuvo multitud de comentarios positivos de las suscriptoras de la organizadora del concurso. Es el efecto relacional de Internet o, en este caso concreto, de YouTube: las suscripciones a un canal hace que sus usuarias estén conectadas en redes, esto permite crear vínculos y tejer relaciones entre las personas. La participación transformó a Sonorona; le generó la vía de su transformación identitaria. Comenzó a crear contenidos sobre makeup y pasó a formar parte plena de la comunidad YouTube, de sus lenguajes y de las narraciones. Después de su 'ingreso' activo en YouTube llegaron otras redes sociales, como Twitter o Instagram, y a medida que su público aumentaba las necesidades de expresión y dominio técnico se incrementaron, llevándola a publicar en multiformato (imagen fija, móvil y texto) y emplear multilenguaje (icónico y textual). 


\subsection{Ser rizomática}

Pero, ¿qué significa ser rizomática? ¿Es algo más que estar en la cultura digital, disponer de sus posibilidades y participar en ella? Para contestar a estas preguntas, hemos de detenernos en algunos aspectos más concretos pero no menos rizomáticos.

\section{a) Dominio y aprendizaje tecnológico}

Sonorona domina el manejo de los artefactos electrónicos que usa asiduamente sin disponer de conocimientos profundos sobre la tecnología en la que se sustentan y sin formación oficial para su aprendizaje. Comenzó a utilizarlos de manera intuitiva, consultando las posibles dudas a otros usuarios amateurs y expertos de trayectorias reconocidas, que probablemente habían llevado a cabo su mismo proceso de aprendizaje informal. En un sentido fuerte, Sonorona es claramente una autodidacta social o, si se prefiere, comunitaria; es decir, su autodidactismo no hubiera podido realizarse sin que otros usuarios y creadores en la Red hubieran compartido sus conocimientos y destrezas con anterioridad. La cuestión clave aquí es que el autodidactismo es posible porque Sonorona es parte misma del rizoma que la cultura digital ha generado. Es el entramado rizomático, el que propicia la plasticidad, multiliteracidad y interconectividad de su aprendizaje.

\section{b) Conexión constante y atención rizomática}

Sonorona es y está inmersa en la tecnología digital; es una usuaria activa y multifacética en dicha cultura. Procesa constante y rápidamente la gran cantidad de información que recibe de múltiples canales; genera nuevas informaciones igualmente de manera rápida y mediante distintos canales y adoptando distintas formas. Ha desarrollado una atención diversificada en varias tareas a la vez, y no por ello las realiza con menor calidad, pasando de unas a otras sin olvidar el conjunto de lo que está haciendo. Sonorona tiene responsabilidades digitales diarias con sus seguidores y seguidoras como son chatear, enviar mensajes, actualizar su blog y fotoblog, crear periódicamente contenidos en distintos formatos, participar en foros, etc.

Al final de cada vídeo recuerdo que puedo resolver dudas a través del mail o las redes sociales. La gente lo usa. Esto crea la responsabilidad de responder. A mí 
como me gusta ayudar a la gente pues lo hago ¿no? respondes o haces la petición (...) me organizo el tiempo. [extracto de entrevista a Sonorona, 2010] ${ }^{11}$

La informante tiene una visión rizomática de su actividad digital; es capaz de estar escuchando música mientras escribe un post en su web o mantiene diversas conversaciones sobre temas distintos de manera simultánea y envía SMS a sus contactos. Manifiesta tantas identidades como ventanas tenga abiertas o tareas diversas está realizando.

La verdad es que lo mismo estoy twitteando con más de una persona a la vez pero también estoy ojeando alguna web de compras o enviando mensajes a mi novio por Whatsapp. Cuando grabo necesito completo silencio pero el resto del tiempo que navego, hago varias cosas a la vez. (...) Cuando estudio necesito concentrarme por eso no suelo conectarme a las redes sociales. [extracto de entrevista a Sonorona, 2010]

La intensidad de su vida en la cultura digital conlleva una actuación digital múltiple (multitasking); pero, quizás sea más iluminador denominar a este estado constante como atención rizomática. Sonorona no está centrada en algo porque no existe un centro en su manera de vivir la cultura digital. Por ejemplo, afirma que no puede leer más de tres páginas seguidas de un libro impreso o un texto digital sin interrumpir la lectura con un chequeo del e-mail o la revisión de los últimos tweets. Como hemos enfatizado, en el rizoma no existe un centro, ni siquiera un centro de atención. Sonorona se desplaza por los intersticios de sus enlaces raíces. Al carecer de centro, Sonorona es ubicua y está y se la encuentra en diversos y variados ámbitos digitales, participando activamente en todos ellos.

\section{c) Hipertextualidad como condición: búsqueda rizomática}

Sonorona suele saber qué busca, pero nunca sabe lo que va a encontrar. En este proceso, el objetivo de la búsqueda va cambiando en función del camino que vaya tomando por el hipertexto. Sonorona valora más el propio proceso que el resultado logrado, sea éste el que fuere. Esto indica que se ha adaptado perfectamente al entramado rizomático en el que se despliega y es, en tanto, Sonorona. Más allá de la hipertextualidad, la cultura digital, en la que vive y contribuye a expandir, es rizomática. 
d) Rizoma sociocomunal: aprendizaje/enseñanza

El modo en que Sonorona aprende y enseña no es sólo informal, es diverso y entrelazado. Adopta múltiples formas/canales: el texto, la imagen, el audio y múltiples plataformas. Pero Sonorona comenzó su participación escribiendo texto, a través de los comentarios que hacía en los vídeos que visionaba en la fase de observación periférica; a este periodo le sucede una etapa en la que la imagen se convierte en el medio predilecto para hacer llegar sus mensaje, terminando por ofrecerlo a modo de hipertexto y combinado mediante texto (web/blog), imagen y sonido (YouTube) o imagen fija (Instagram). En todas estas herramientas es posible combinar los formatos. Un ejemplo de ello es este post: http://www.sonorona.com/ 2014/11/katvond-maquillaje-inspirado-neutral.html.

Esta múltiple forma de exposición de los contenidos ofrece la posibilidad a sus seguidores/as y a sus compañeros/as webactores/actrices de seleccionar, a su vez, los trayectos de exploración de sus contenidos, tal y como ella lo hacía cuando se limitaba a consumir los contenidos de otros/as. En este sentido, la relación es plenamente rizomática; acceder a información en la cultura digital conlleva una navegación, a su vez, rizomática: permite una participación diversa y relacionada con el usuario, nunca impuesta desde la estructura.

\subsubsection{La participación rizomática}

Sonorona no es una persona aislada, aprende en interacción con y de los demás. La producción de conocimiento y la adopción y apropiación de otros en la cultura digital se apoya en un claro compromiso y participación activa: "Es un trabajo conjunto... me piden opinión... pero yo también he aprendido de otras a las que les he pedido consejos que ahora me piden y doy yo" [extracto de entrevista a Sonorona, 2010]. El rizoma funciona en ambos sentidos: de Sonorona a sus contactos y viceversa. Los rizomas se convierten en nuevos rizomas, la red crece y se extiende. El rizoma es un principio identitario democrático, abierto y expansivo a sus usuarios. No impone, sino que permite; no restringe, sino que amplifica. 


\subsection{Copia/recreación/creación: un posible trayecto en la cultura} digital rizomática

El proceso de creación de contenidos de Sonorona se ha desarrollado a lo largo de su conversión rizomática, a través de varios momentos entrelazados y desarrollados, a veces, de modo simultáneo.

\section{a) Copia (+paste), la imitación como punto inicial}

Se trata de imitar lo que aquellas otras youtubers y webactrices hacen con sus propios recursos y que parece resultar adecuado a juzgar por los comentarios positivos recibidos. Ejemplos son las reseñas de productos valorados por otras prosumidoras, un look o temáticas como compras o productos terminados.

\section{b) De la copia a la recreación}

La práctica de copia no es nunca copia literal; algo se modifica cuando creemos poner elementos literales en los intersticios del rizoma: el rizoma lo altera todo, lo cambia, al comentarlo, al ofrecerlo. Además, en el rizoma, las opiniones ('positivas y negativas') de los usuarios, no sólo contribuyen a la noliteralidad del producto, sino que se convierte en elementos clave de creación rizomática. Esta información positiva y negativa es procesada y utilizada por Sonorona como argumento para cambios y/o mantenimiento de comportamientos y contenidos posteriormente. El feedback de su público orienta las nuevas prácticas, bien afianzándolas o bien modificándolas. La percepción, la comparación, la confrontación, el análisis y el espíritu crítico son estrategias cognitivas importantes en este momento.

También aprendo de los comentarios que me hacen y críticas constructivas. La gente me dice lo que le gusta y lo que no sobre los looks o sobre cómo hablo, así que estoy alerta y mejoro. Echo en falta comentarios relacionados con la informática porque sé que hay mucha gente que sabe y quizás me ve pero comenta más sobre los contenidos que sobre la técnica. [extracto de entrevista a Sonorona, 2010]

\section{Ejemplos:}

http://www.youtube.com/watch?v=BuL0OIkcORE\&feature= channel\&list=UL 
http://www.youtube.com/watch?v=0jl_76sdh4Q\&feature= channel\&list $=U L$

\section{c) Creación rizomática, inspiración cultural}

Cuando Sonorona se siente youtubera, comienza a crear elementos nuevos sobre los elementos originales copiados y recreados. En esta fase, ha adquirido ciertas técnicas, un fuerte sentido estético, un pensamiento divergente y un conocimiento profundo de materiales y de productos. Se ha alejado de patrones y modelos (de los que ha aprendido), su identidad se ve desarrollada y las visitas a sus producciones son más frecuentes, aumentándose el número de suscripciones.

Las producciones son diversas en formato y contenido en función de la herramienta de difusión y creación: Así, YouTube se usa para tutoriales, reviews y houls (más tipo muestrario o expositivo) dirigidos a una gran audiencia; la Web para fotografías, intercambio de opiniones hacia una gran audiencia; y las redes sociales para el intercambio comunicativo con seguidoras y compañeras, un público más individualizado.

\section{El rizoma de Sonorona, la raíz de María}

Sonorona es un sujeto rizomático, que convive con un sujeto arbóreo/raíz que es María. Sonorona se despliega en el entorno digital, como participante rizomática activa; María vive también en un mundo no expresamente rizomático, pero que también está transido por lo digital. La cuestión aquí se encuentra en que no podemos hablar de un mundo digital exclusivo y un mundo físico excluyente. Poner el énfasis en el contexto digital y en su estructura rizomática implica repensar también María como parte de este ambiente. María y Sonorona están identitariamente entretejidas. Pero ¿qué las diferencia a una y a otra, si ambas viven en y con la cultura digital? Quizás la respuesta se encuentre metafóricamente en que, como decíamos, María es un árbol y Sonorona un rizoma digital.

- Sonorona como rizoma digital es fruto de su participación y de la negociación de su experiencia como creadora y consumidora de contenidos. Se define y determina por el modo y nivel de participación en las distintas aplicaciones y redes en las que 
interviene y por las respuestas que recibe. Es generadora de contenidos en su canal, colaboradora en el canal grupal, pero también es consumidora de otras producciones y moderadora de debates en los blogtv.

- Sonorona es definida en y por las comunidades a las que pertenece (belleza, cosmética o moda). Pero, a partir de su pertenencia a éstas, se ha introducido en otras comunidades sobre fotografía, música, dibujo, manualidades, series o cine. La identidad rizomática de Sonorona, cambiante, fluida, evolutiva y dinámica, es profunda.

- La implicación en las distintas comunidades y redes surge de la necesidad por buscar información y prácticas interesantes. Ello quiere decir que el principio del rizoma para Sonorona es cognitivo; es, por decirlo de un modo rotundo, epistémico, luego podrá ser otra cosa. A su vez, el rizoma es movimiento, búsqueda constante, que define a Sonorona a partir de lo que busca, de lo que comparte y de lo que le gusta o no le gusta, lo que compra o no compra. Sonorona es coqueta, curiosa, atenta, colaboradora, solidaria, comunicativa, generosa; es, repetimos, una identidad rizomática.

- La identidad de Sonorona, por lo tanto, es fruto de múltiples relaciones rizomáticas de distinta índole. En torno a esta identidad giran distintos ámbitos de su vida en el mundo virtual: el ámbito social dentro de las redes sociales; el ámbito formativo de modo informal a través de los canales de YouTube, foros, redes sociales como Twitter o Facebook, portales como Formspring, de distintos contenidos; el ámbito laboral a través de webs o portales laborales. La pertenencia a las distintas comunidades favorece esta pluralidad y más en las comunidades virtuales, en las que los horizontes y los límites son tan lejanos y en las que se comporta y expresa de modo distinto en cada una de ellas, construyendo diferentes aspectos de ella misma. Hablamos de la construcción de la identidad, que es tanto social como individual, y esta individualidad se forja a través de las prácticas en las comunidades sociales a las que pertenece (Wenger, 2001). 
En el nuevo mundo digital, Sonorona se vuelve nómada, plural, heterogénea, posee múltiples identidades y es exploradora de nuevos espacios y mundos, lo que hace que su identidad sea, más que nunca, inestable y dinámica. Como nos dice Turkle (1997), somos "fluidos, emergentes, descentralizados, múltiples, flexibles y constantemente en proceso" (pp. 263-264). La persona es una pero se desenvuelve de manera distinta en los diferentes contextos en los que se desarrolla. Los nexos entre sus modos de comportamiento no van en una única trayectoria sino en múltiples, en la que cada una es parte de las demás. Es al mismo tiempo una $y$ varias identidades.

El sentimiento de pertenencia es plural, el caso pertenece a muchos lugares, redes, personas y comunidades a la vez (redes sociales, portales, colectivos, etc.). El "soy un/a..." seguido de una categoría no tiene el valor ni el peso que tenía antaño, puesto que pertenece a una multitud de categorías. Su arraigo a diversas categorías dispares pero compatibles entre sí rompe con un orden de prioridades jerárquico del ser a favor de una relación horizontal y rizomática. Es un ser distribuido, ubicuo, es lo uno y lo otro al mismo tiempo. Es posible, por tanto, proyectar tantas imágenes como variedad de espacios donde lo haga. Así, la identidad se conforma como constructo vivo, modificable, renovado, ampliado e incluso corregido. En conjunto, María/Sonorona es/son muchas "personas": unas veces maestra, otras alumna, otras vendedora, publicista, maquilladora, crítica de productos, artista, creativa, presentadora, experta, amateur. Este es un concepto que Google ha incorporado recientemente en su red Google+ de forma óptima, ya que el modo de interactuar en cada uno de nuestros círculos suele ser diferente. Según Glissant (1996), "(...) la identidad no sólo se encuentra en la raíz, sino también en la relación" (p. 12), pero la relación digital no es una nueva y simple raíz, es un rizoma.

De un modo o de otro, la identidad se bifurca y es cambiante según experiencias y ambientes, pero lo que las diferencia es que, mientras que las teorías dicotómicas promulgan que se bifurcan desde un único nudo o raíz formando otras inferiores, la rizomática de la que aquí hablamos no sólo es múltiple, sino que se construye en un proceso permanente y perpetuo en el que se es en relación con los otros cuyas identidades son igualmente cambiantes. Son construidas a partir de un proceso de individualización 
(Giddens, 1991) y autodefinición. El sentido se organiza en torno a una identidad que se sostiene por sí misma y que enmarca al resto.

De todo ello, siguiendo a Wenger (2001), podemos deducir que la identidad podría caracterizarse por ser:

a) Vivida: no puede simplificarse en roles, categorías o rasgos concretos, sino en ellos y en la relación entre tales roles, categorías o rasgos que somos capaces de ejercer y que nos definen.

b) Negociada: se construye de forma permanente y en todo lugar, no está reducida ni a contextos determinados ni a tiempos concretos.

c) Social: la identidad se conforma con otros y en función de ellos, será de una manera o de otra al igual que nosotros conformamos la de los demás en un proceso bidireccional.

d) Proceso de aprendizaje e imaginativa: la identidad es hoy en función de lo que fue ayer y de lo que desea ser, convirtiéndose en un ejercicio de reflexión y confrontación entre lo real y lo deseable.

e) Un nexo: fruto de la conciliación de los distintos modos de actuar y pensar en función de la comunidad y del contexto en el que nos ubiquemos.

f) Una interacción local-global: fruto de la interacción entre lo más cercano y en lo que participa con lo más lejano y distante a sus prácticas, lo más global. Es a lo que Wellmann llamaría identidades glocalizadas (2002) y Pisani \& Piotet (2009) identidad translocal (p. $60)$.

La actuación de Sonorona en los distintos agrupamientos y comunidades a las que se afilia se convierten en elemento que configura su identidad. Su identidad, más que nunca, tiene la posibilidad de desarrollarse en contextos ilimitados y las herramientas digitales se convierten en medios idóneos para ello. Jeaffrey Boase apoya esta idea en las siguientes palabras:

(...) en una aldea, todo el mundo se conoce. Hoy nuestras redes están mucho más diversificadas y más extendidas. Tenemos más libertad para elegir entre distintos tipos de relación y para mantener aquellas que queremos mantener. (cit. en Pisani \& Piotet, 2009, p. 62) 


\subsection{Sobre el uso rizomático de las tecnologías}

Si la identidad de María es rizomática, también lo es el uso de la propia tecnología. Va pasando de unas herramientas a otras debido a las nuevas necesidades que le surgen y las nuevas ofertas que derivan de tales herramientas. El uso de nuevos medios y herramientas evolucionan a medida que lo hace Sonorona; se adapta, se transforma. De este modo, los canales, plataformas y herramientas que utiliza coexisten en la mayor parte de los casos o son una extensión y mejora de los ya existentes. En otros casos, se sustituyen.

La tecnología es en sí misma también un rizoma. No en vano, la mayor parte de las redes sociales, creadas en principio para crear imagen móvil (caso de YouTube) o texto (caso de blogs), han ido convirtiéndose en herramientas multiformato; impera el todo en uno. Tenemos el ejemplo de Facebook como plataforma unificada. Estando y siendo en esta red social, Sonorona puede ser rizoma en otros tantos lugares. Facebook es un espacio que simplifica el trabajo de publicación de nuestra informante debido a que, a pesar de ser una red social, en ella se aglutinan distintas funcionalidades que estaban separadas en distintas webs: e-mail, agendas, chat, juegos, foros, entre otros. A medida que el tiempo pasa y que el público va aumentando, se va haciendo necesaria la evolución del uso de distintas herramientas cada vez más diversas y complementarias, al igual que lo son las personas o usuarios que consumen y coproducen sus materiales.

\subsection{El nick como primera seña de identidad}

El nick de Sonorona, primer rasgo de su identidad rizomática en la Red (y también fuera de ella), podría configurarse como elemento-frontera entre lo público y lo privado. Así, Sonorona sería su identidad más pública, y utiliza este nick en lo relacionado a sus producciones y relaciones con suscriptoras. María como nombre es utilizado para ser y hacer dentro de la pantalla de modo más privado. Sólo revela aquella información que desee acerca de ella misma, dependiendo de la identidad de la que se trate. No se trata de mentir, sino de mostrar sólo lo necesario para poder participar activamente en las comunidades virtuales a las que pertenece o aquello relativo a la temática de los contenidos que produce. De este modo, salvaguarda y aparta de la mirada ajena a sus familiares y sus amistades. 
Sonorona es la identidad digital que ha pasado a ser parte de María como una identidad más de otras tantas en ella, dentro y fuera de lo digital. La pluralidad de gestiones, contextos y personas con las que interactúa ofrecen la oportunidad igualmente diversa que provoca el cumplimiento de roles que fragmentan su yo en múltiples identidades o yoes. Pero esos distintos yoes no se aíslan del yo físico ni de María, sino que forman parte de ella. De hecho, no podemos establecer dónde empieza una y acaba la otra. $\mathrm{Y}$ en parte esto es así porque precisamente no hay tanta distinción entre ambos mundos, sino que se complementan y se influyen en uno con el otro. Son personajes vividos por las webactrices como parte de ella misma y se identifica con ellas.

\section{La borrosa y delgada línea que separa lo digital de lo no digital}

A pesar de que entendamos a Sonorona como rizoma, somos conscientes que esta identidad influye en su vida offline. Sonorona no sólo es y está en la pantalla, sino fuera de ella. Su vida digital y no digital no son paralelas ni distantes, sino en continua relación, están entrelazadas. Por un lado, sus relaciones establecidas en el entorno físico pueden ser continuadas, mantenidas y profundizadas a través de Internet y, por otro lado, se podrían establecer contactos de forma virtual y afianzar las relaciones en el espacio físico. Facebook es un ejemplo de lo que decimos. Su perfil en principio fue creado con el objetivo de mantener virtualmente contactos que comenzaron y afianzaron en el entorno no digital, en concreto en el contexto educativo universitario.

De hecho, ambos mundos se funden y confluyen. Existe un trabazón entro lo virtual y lo no virtual. Sonorona está dentro y fuera de las herramientas digitales, pero María también está dentro y fuera; son identidades complementarias, son dos universos en la misma persona. Hacen cosas distintas en cada esfera, pero también parecidas, interrelacionadas y adicionales. La experiencia offline y online se comparten, se combinan y se entrelazan. Lo que hace y es como Sonorona repercute en María y viceversa; por ello, no es tarea sencilla determinar dónde comienza una y termina la otra, si es que algo así fuera posible. 
Ejemplo de esta línea desdibujada en la que lo físico y lo virtual se confunden son las potiquedadas ${ }^{12}$. Es una muestra de que lo que comienza en lo digital no tiene por qué acabar ahí o viceversa. No deja de ser Sonorona en lo no digital ni tampoco deja de ser María en lo digital. De hecho, las otras participantes en este encuentro nombran a María por Sonorona, aunque su relación se haya establecido dentro del contexto digital rizomático de Sonorona, pero en ese momento estén en el mundo físico.

\section{Una última reflexión rizomática}

María o Sonorona, y otros tantos prosumidores, lee y escucha escribiendo y hablando; aprende haciendo y comunicándose, participando, viviendo y relacionándose, buscando y investigando, compartiendo sus logros y desencuentros; aprende enseñando y enseña aprendiendo. Su identidad se conforma con otros y por otros al igual que otros son otros por ella y con ella, y la horizontalidad cultural impera.

Lejos de que lo virtual sea irreal, es mucho más real de lo que podría imaginarse. Es tan real que tiene muchas más vivencias, conoce más, sabe más de todo, o al menos sabe dónde localizar información sobre lo que le interesa. Abre su intimidad como profesional a otros, a quienes no ha visto nunca y quizás nunca vea; comparte inquietudes y secretos, penas y alegrías, información y conocimientos, y esto ocurre porque lo que sucede en Internet es reflejo y repercute lo que ocurre fuera de ella y porque lo que ocurre fuera de ella repercute y es reflejo de lo que ocurre dentro. Ambos contextos, como ambas identidades (Sonorona/María), cual rizoma, conviven en armonía, pudiendo ramificarse en otras tantas identidades desde cualquier punto y en relación horizontal con las ya existentes y con las que se relaciona de forma simultánea y recíproca, haciendo que crezcan y se desarrollen entre sí, siendo la solidez otorgada por María como identidad primera (que no primaria).

\section{Notas}

1 Este trabajo ha sido posible gracias al Proyecto de Excelencia "Escenarios, Tecnologías digitales y Juventud en Andalucía", con referencia P07-HUM-02599, financiado por la Junta de Andalucía, Consejería de Innovación, Ciencia y Empresa. El estudio de caso, ampliado, formó parte de la investigación "Nuevas formas de 
hacer, nuevas formas de ser: Las tecnologías digitales como agentes dinamizadores del aprendizaje informal", tesis doctoral de Dña. Mónica López Gil y dirigida por el Catedrático de Educación y Organización escolar D. J. Félix Angulo Rasco, ambos PDI de la Universidad de Cádiz.

2 Oppenheimer (2004) los llama tecnoevangelistas. También Thomas (2011) insiste en esta calificación: "(...) el discurso de los nativos digitales en su forma simplificada puede ser considerado un tipo de tecnoevangelismo" (p. 4).

3 Determinismo que también se encuentra en Negroponte (1995) y en Kerckhove (1995).

4 La idea de entorno densamente tecnologizado ha sido desarrollada en Angulo Rasco y Vázquez Recio (2010).

5 Como ha indicado Gere (2002:), con el adjetivo de digital "(...) se invoca un 'marcador' (determinante) de la cultura que abarca tanto artefactos como sistemas de significación y comunicación que más claramente demarcan nuestra vida contemporánea de las anteriores" (p. 13). Prensky (2011a), en un marcado cambio con respecto a enfoques anteriores, enfatiza también la idea de cultura.

6 Algo que supo ver Gubern $(1987,1992)$. Una excelente análisis histórico es el de Briggs y Burke (2002).

7 Gere (2002) plantea el surgimiento de la cultura digital de una manera más sociohistórica que medial.

8 Weinberger $(2005,2007)$ apunta a algo mucho más complejo que a las folksonomías.

9 Un análisis crítico del concepto se encuentra en Reynoso (2012).

10 Red social española muy conocida entre los jóvenes veinteañeros: http://www.tuenti.com

11 Para su mayor comprensión se ha adaptado la sintaxis y expresión de esta cita evitando oralismos.

12 Encuentros físicos entre youtuberas relacionadas con el maquillaje y cosmética.

\section{Referencias}

Angrosino, M., \& Rosenberg, J. (2011). Observations on observation: Continuities and challenges. In N. K. Denzin \& Y. S. Lincoln (Eds.), The SAGE handbook of qualitative research (pp. 467-478). Thousand Oaks: Sage Publications.

Angulo Rasco, J. F. (2008). Novos espaços para a alfabetização. In J. M. Paraskeva \& L. R. Oliveira (Orgs.), Currículo e tecnologia educativa (Vol. 2, pp. 87-116). Mangualde: Edições Pedago.

Angulo Rasco, J. F., \& Bernal, C. (2012). The ICT as a discourse of salvation. In J. M. Paraskeva \& J. Torres (Ed.), Globalism and power. Iberian education and curriculum policies (pp. 107-120). New York: Peter Lang.

Angulo Rasco, J. F., \& Vázquez Recio, R. (2003). Introducción a los estudios de caso. Málaga: Aljibe. 
Angulo Rasco, J. F., \& Vázquez Recio, R. (2010). El currículum y los nuevos espacios para aprender. In J. Gimeno Sacristán (Ed.), Saberes e incertidumbres sobre el curriculum (pp. 501-526). Madrid: Morata.

Ante, S. E., \& Holahan, C. (2008). Generation MySpace is getting fed up. Bloomberg Businessweek. Recuperado de http://www.businessweek.com/magazine/ content/08_07/b4071054390809.htm

Becker, H. (1995). Visual sociology, documentary photography or photojournalism (almost) all a matter of context. Visual Sociology, 10(1-2), 5-14.

Bolter, J. D., \& Grusin, R. (1999). Remediation. Understanding new media. Cambridge, MA: The MIT Press.

Briggs, A., \& Burke, P. (2002). De Gutenberg a Internet. Una historia social de los medios de comunicación. Madrid: Taurus.

Burgess, J., \& Green, J- (2009). YouTube: Online video and participatory culture. Cambridge: Polity Press.

Castells, M. (1997). La sociedad red. Madrid: Alianza.

Castells, M. (2001). La galaxia Internet. Madrid: Areté.

Castells, M. J. (2006). Mobile communication and society. A global perspective. Cambridge: MIT.

Creswell, J. W. (2011). Controversies in mixed methods research. In N. K. Denzin \& Y. S. Lincoln (Eds.), The SAGE handbook of qualitative research (pp. 269-284). Thousand Oaks: Sage Publications.

Deleuze, G., \& Guattari, F. (1971). El anti-Edipo. Barcelona: Barral.

Deleuze, G., \& Guattari, F. (1997). Rizoma - Introducción. Valencia: Pre-textos.

Denzin, N. K. (1997). Interpretive ethnography. Ethnograhic practices for the 21st century. London: Sage.

Echeverría, J. (1999). Los señores del aire: Telépolis y el tercer entorno. Barcelona: Destino.

Facer, K., Furlong, J., \& Furlong, R. (2003). ScreenPlay. Children and computing in the home. London: RoutledgeFAlmer.

Gere, C. (2002). Digital culture. London: Reaction Books.

Giddens, A. (1991). Modernity and self-identity. Self and society in the late modern age. Oxford: Polity Press.

Glissant, E. (1996). Introducción a una poética de lo diverso. Barcelona: Ediciones del Bronce.

Gubern, R. (1987). El simio informatizado. Madrid: Fundesco.

Gubern, R. (1992). La mirada opulenta. Exploración de la iconosfera contemporánea. Barcelona: Gustavo Gili.

Hine, C. (2000). Virtual ethnography. London: Sage.

Hutchby, I., \& Moran-Ellis, J. (Eds.). (2001). Children, technology and culture: The impacts of technologies in children's everyday lives. London: Routledge.

Ito, M. (2010). Hanging out, messing around, and geeking out. Kids living and learning with new media. Cambridge/London: The MIT Press. 
Kerckove, D. (1997). Connected intelligences: The arrival of the web society. Toronto: Somerville House.

Kozinets, R. V. (2010). Netnography. Doing ethnographic research online. London: Sage.

Kress, G. (2010). The profound shift of digital literacies. In J. Gillen \& D. Barton (Eds.), Digital literacies (pp. 6-7). London: London Knowledge Lab. Recuperado de http://www.tlrp.org/docs/DigitalLiteracies.pdf

Mann, C., \& Stewart, F. (2000). Internet communication and qualitative research: $A$ handbook for researching online. London: Sage.

Miller, D., \& Slater, D. (2000). The Internet. An ethnographic approach. Oxford: Berg.

Negroponte, N. (1995). Being digital. New York: Random House.

Oppenheimer, T. (2004). The flickering mind. Saving education from the false promise of technology. New York: Random House.

Orlet, C. (2007, February 3rd). The look-at-me-generation. The American Spectator. Recuperado de http://spectator.org/archives/2007/03/02/ the-look-at-megeneration

Pink, S. (2007). Doing visual ethnography. London: Sage.

Pisani, F., \& Piotet, D. (2009). La alquimia de las multitudes: Cómo la Web está cambiando el mundo. Barcelona: Paidós.

Prensky, M. (2001b). Digital natives, digital immigrants: Do they really think differently? On the Horizon, 9(6), 1-6.

Prensky, M. (2011a). Digital wisdom and homo sapiens digital. In M. Tomas (Ed.), Deconstructing digital natives. Young people, technology and the new literacies (pp. 15-29). London: Routledge:

Prensky, M. (2011b). From digital natives to digital wisdom. Hopeful essays for $21 \mathrm{st}$ century learning. London: Corwin.

Presky, M. (2001a). Digital natives, digital immigrants. On the Horizon, 9(5), 1-6.

Prosser, J. D. (2011). Visual methodology: Toward a more seeing research. In N. K. Denzin \& Y. S. Lincoln (Eds.), The SAGE handbook of qualitative research (pp. 479-496). Thousand Oaks: Sage Publications.

Reynoso, C. (2012). Árboles y redes: Crítica del pensamiento rizomático. Recuperado de http://carlosreynoso.com.ar

Sefton-Green, J. (1998). Introduction: Being young in the digital age. In J. Sefton-Green (Ed.), Digital diversions: Youth culture in the age of multimedia (pp. 1-18). London: UCL Press.

Simons, H. (2011). El estudio de caso: Teoría y práctica. Madrid: Morata.

Sonvilla-Weiss, S. (Ed.). (2010). Mashup cultures. Wien: Springer-Verlag.

Spradley, J. P. (1980). Participant observation. New York: Holt, Rinehart and Winston.

Stake, R. (1995). The art of case study research. London: Sage.

Tapscott, D. (1998). Grown up digital: How the Net generation is changing your world. New York: McGraw Hill. 
Thomas, M. (2011). Technology, education and the discourse of the digital native: Between evangelists and dissenters. In M. Thomas (Ed.), Deconstructing digital natives. Young people, technology and the new literacies (pp. 1-14). London: Routledge.

Turkle, S. (1997). La vida en la pantalla: La construcción de la identidad en la era de Internet. Paidós: Barcelona.

Warschauer, M. (1999). Electronic literacies. Language, culture and power in online education. Mahwah, NJ: Lawrence Erlbaum Associates.

Weinberger, D. (2005). Taxonomies to tags: From trees to piles of leaves. Release 1.0, 23(2), 2-33.

Weinberger, D. (2007). Everything is miscellaneous. The power of the new digital disorder. New York: Times Books.

Wellmann, B. (2002). The rise (and possible fall) of networked individualism. Recuperado de www.insna.org/PDF/Connections/v24/2001_l-3-4.pdf.

Wenger, E. (2001). Comunidades de práctica: Aprendizaje, significado e identidad. Barcelona: Paidós.

Westby, C. E. (1990). Ethnographic interviewing: Asking the right questions to the right people in the right ways. Communication Disorders Quarterly, 13(1), 101-111.

Williams, P., \& Rowlands, I. (2007). Information behaviour of the researcher of the future. The literature on young people and their information behavior - Work Package II. A British Library/JISC Study. Recuperado de http://www.jisc.ac.uk/ media/documents/programmes/reppres/ggworkpackageii.pdf

Yin, R. K. (1994). Case study research: Design and methods. Londres: Sage. 


\section{SONORONA OR DIGITAL CULTURE RHIZOME. A CASE STUDY}

\section{Abstract}

This paper presents the case study of Sonorona, Maria's nickname, a young girl aged 22. Sonorona is a 'makeup guru' in Spain. She is a youtuber and blogger's girl. This study aimed to analyze the comprehension and participation of young people in mediatic and technological culture. It intends to continue the works by Sefton-Green (1998), Hutchby and Moran-Ellis (2001) and Facer, Furlong and Furlong (2003), among others, in what is related to the profound changes that lead to the emergence of technological advances, setting up what we might call a new cultural paradigm characterized by the digital. Technologies that surround us and with which we live have transformed the way people interact with each other, but also how we relate to information and knowledge and how identity develops.

Keywords

Digital literacy; Network identity; Youth; Informal education

SONORONA O EL RIZOMA DE LA CULTURA DIGITAL. UN ESTUDIO DE CASO

\section{Resumen}

Este artículo tiene el fin de presentar el estudio de caso de Sonorona, nick de María, una joven de 22 años "youtubera" y "bloguera". La realización de este estudio de caso tenía el objetivo de analizar la comprensión y participación que tiene la juventud en la cultura mediática y tecnológica que la rodea. Este fin va en la línea de los estudios de Sefton-Green (1998), Hutchby y MoranEllis (2001), Facer, Furlong, y Furlong (2003), entre otros, en relación a los cambios profundos que han provocado la irrupción de los avances tecnológicos, configurando incluso lo que podríamos llamar un nuevo paradigma cultural caracterizado por lo digital. Las tecnologías que nos 
rodean y con las que convivimos han transformado el modo en que las personas se relacionan, pero también el modo de relacionarnos con la información y el conocimiento y el modo en que se desarrolla la identidad.

Palabras-clave

Alfabetización digital; Identidad en la Red; Juventud; Educación informal

Recebido em fevereiro/2015

Aceite para publicação em maio/2015 i Departamento de Didáctica, Facultad de Ciencias de la Educación, Universidad de Cádiz,
España.

ii Departamento de Didáctica, Facultad de Ciencias de la Educación, Universidad de Cádiz, España.

Toda a correspondência relativa a este artigo deve ser enviada para: Mónica María López Gil, Facultad de Ciencias de la Educación, Campus Universitario de Puerto Real, 11510 Puerto Real, Cádiz, España. E-mail: monica.maria@uca.es 